\section{(1) \\ CrossMark}

\title{
A virtual asthma clinic for children: fewer routine outpatient visits, same asthma control
}

\author{
Lara S. van den Wijngaart ${ }^{1}$, Jolt Roukema ${ }^{1}$, Annemie L.M. Boehmer ${ }^{2}$, \\ Marianne L. Brouwer ${ }^{3}$, Cindy A.C. Hugen ${ }^{1}$, Laetitia E.M. Niers ${ }^{4}$, Arwen J. Sprij ${ }^{5}$, \\ Eleonora R.V.M. Rikkers-Mutsaerts ${ }^{6}$, Bart L. Rottier ${ }^{7}$, A. Rogier T. Donders ${ }^{8}$, \\ Chris M. Verhaak ${ }^{9}$, Mariëlle W. Pijnenburg ${ }^{10}$ and Peter J.F.M. Merkus ${ }^{1}$
}

\begin{abstract}
Affiliations: 'Dept of Paediatric Pulmonology, Amalia Children's Hospital, Radboud University Medical Centre, Nijmegen, The Netherlands. ${ }^{2}$ Dept of Paediatrics, Maasstad Hospital, Rotterdam, The Netherlands. ${ }^{3}$ Dept of Paediatrics, Canisius Wilhelmina Hospital, Nijmegen, The Netherlands. ${ }^{4}$ Dept of Paediatrics, Maxima Medical Centre, Veldhoven, The Netherlands. ${ }^{5}$ Dept of Paediatric Pulmonology, Juliana Children's Hospital, Haga Hospital, The Hague, The Netherlands. 'Dept of Paediatric Pulmonology, Leiden University Medical Centre, Leiden, The Netherlands. ${ }^{7}$ Paediatric Pulmonology and Allergology, Groningen Research Institute for Asthma and COPD, Beatrix Children's Hospital, University of Groningen, University Medical Centre Groningen, Groningen, The Netherlands. ${ }^{8}$ Dept for Health Evidence, Radboud University Medical Centre, Nijmegen, The Netherlands. ${ }^{9}$ Dept of Psychology, Radboud University Medical Centre, Nijmegen, The Netherlands. ${ }^{10}$ Dept of Paediatric Pulmonology, Sophia Children's Hospital, Erasmus Medical Centre, Rotterdam, The Netherlands.
\end{abstract}

Correspondence: Lara S. van den Wijngaart, Dept of Paediatric Pulmonology, Amalia Children's Hospital, Radboud University Medical Centre, PO 9101, 6500 HB Nijmegen, The Netherlands. E-mail: lara. vandenwijngaartaradboudumc.nl

@ERSpublications

A virtual asthma clinic as an individualised online monitoring strategy can partly replace routine outpatient visits http://ow.ly/f9Vd30dqWvJ

Cite this article as: van den Wijngaart LS, Roukema J, Boehmer ALM, et al. A virtual asthma clinic for children: fewer routine outpatient visits, same asthma control. Eur Respir J 2017; 50: 1700471 [https://doi. org/10.1183/13993003.00471-2017].

ABSTRACT eHealth is an appealing medium to improve healthcare and its value (in addition to standard care) has been assessed in previous studies. We aimed to assess whether an eHealth intervention could improve asthma control while reducing $50 \%$ of routine outpatient visits.

In a multicentre, randomised controlled trial with a 16-month follow-up, asthmatic children (616 years) treated in eight Dutch hospitals were randomised to usual care (4-monthly outpatient visits) and online care using a virtual asthma clinic (VAC) (8-monthly outpatient visits with monthly web-based monitoring). Outcome measures were the number of symptom-free days in the last 4 weeks of the study, asthma control, forced expiratory volume in $1 \mathrm{~s}$, exhaled nitric oxide fraction, asthma exacerbations, unscheduled outpatient visits, hospital admissions, daily dose of inhaled corticosteroids and courses of systemic corticosteroids.

We included 210 children. After follow-up, symptom-free days differed statistically between the usual care and VAC groups (difference of 1.23 days, 95\% CI 0.42-2.04; $\mathrm{p}=0.003$ ) in favour of the VAC. In terms of asthma control, the Childhood Asthma Control Test improved more in the VAC group (difference of 1.17 points, $95 \%$ CI $0.09-2.25 ; \mathrm{p}=0.03$ ). No differences were found for other outcome measures.

Routine outpatient visits can partly be replaced by monitoring asthmatic children via eHealth. 


\section{Introduction}

The introduction of eHealth in healthcare undeniably offers new possibilities to change the way healthcare is organised. With respect to asthma, some individual studies in adults have suggested that eHealth may reduce the number of acute asthma exacerbations, emergency department visits and hospital admissions [1-3]. However, systematic reviews focusing on the effectiveness of eHealth have shown that high-quality evidence for impact on clinical end-points is still limited, inconsistent and often measured over the short term [4-6]. In paediatric asthma management, studies are even scarcer and only assessed the value of eHealth interventions in addition to standard care, rather than replacing it [7-12]. Implementation of eHealth in clinical practice is still limited and, to date, eHealth has no place in paediatric asthma management [13].

Several questions about the role of eHealth in asthma care still remain. Is eHealth just an eternal promise or does it already provide an opportunity to optimise asthma management and improve asthma control? Can eHealth replace routine outpatient visits? To answer these questions, we used a virtual asthma clinic (VAC) to assess whether asthma control could be improved while substituting $50 \%$ of routine outpatient visits. We hypothesised that online monitoring of asthma was superior to usual care.

\section{Methods}

\section{Study design}

This was a prospective, multicentre, randomised, unblinded controlled trial on the effects of the VAC in asthmatic children, in comparison with usual care asthma management. This 16-month study was conducted in four general hospitals and four tertiary referral centres in the Netherlands. Asthma management was based on Dutch guidelines that resemble Global Initiative for Asthma guidelines closely [14], but subtle differences between centres could exist. To control for such differences, participants were randomised within each centre in permuted blocks of four or six into one of the two monitoring strategies after stratification for age (young children (6-11 years) or older children (12-16 years)) (figure 1). Randomisation was conducted centrally using a computer-generated randomisation schedule. This study was approved by all local ethics committees. All parents and all children $\geqslant 12$ years gave written informed consent and assent, respectively. Results of this randomised controlled trial were presented at the Congress of the European Respiratory Society, Amsterdam, 2015.

\section{Participants}

Eligible participants were children (6-16 years) with a doctor's diagnosis of asthma based on symptoms and a bronchodilator response of forced expiratory volume in $1 \mathrm{~s}(\mathrm{FEV} 1) \%$ pred $>9 \%$, and/or airway hyperresponsiveness, and/or signs of eosinophilic airways inflammation (elevated exhaled nitric oxide fraction $(F \mathrm{ENO})>25 \mathrm{ppb}$ ). All had to have at least one allergy for airborne allergens confirmed by positive skin prick tests and/or blood tests, and have a computer with internet access. Exclusion criteria were a history of admission to the intensive care unit for asthma in the preceding 5 years, difficult-to-treat asthma (defined as uncontrolled or poorly controlled asthma in spite of maintenance treatment with inhaled corticosteroids (ICSs) with at least $800 \mu \mathrm{g} \cdot \mathrm{day}^{-1}$ regular beclomethasone or equivalent, long-acting bronchodilators and/or montelukast, and/or oral corticosteroids), use of omalizumab, other chronic diseases, and the inability of the parents or children to read and understand Dutch.

\section{Patient involvement}

Paediatric pulmonologists developed the research questions taking into account patient's experiences with current care. Focus group interviews were held to explore participants' wishes and possible objections against the VAC. Main preferences were used to develop the VAC: a web-based portal with a chat and forum module for peers, an information module to enhance knowledge about asthma, and a secure and private module in which the child/parent can log in to consult (or download) an individual treatment plan and communicate with the asthma management team. Participation was accompanied with several

This article has supplementary material available from erj.ersjournals.com

Received: March 072017 | Accepted after revision: July 022017

This study is registered at www.trialregister.nl with identifier number NTR 2689.

Support statement: This study was funded by Lung Foundation Netherlands (grant number 3.4.10.016) and Dutch Innovation Foundation Health insurance companies (grant number B 10-135). The funders had no role in trial design, data collection, analysis or reporting. Funding information for this article has been deposited with the Crossref Funder Registry.

Conflict of interest: Disclosures can be found alongside this article at erj.ersjournals.com 
psychosocial and cost-specific questionnaires alongside the trial. However, both children and parents disapproved of the idea of daily questionnaires during the last month of the study to assess the number of symptoms-free days (SFDs), since this would not reflect real-life use of the VAC in daily practice and would constitute too much of an additional burden for them. Therefore, the number of SFDs was calculated based on two questions from the (Childhood) Asthma Control Test ((C-)ACT) based on the last month of the study instead of a diary (see supplementary appendix S1).

\section{Interventions}

Prior to the study, each centre received information about the intervention and was trained according to the study protocol. All children and their parents received standardised instructions concerning inhalation technique, use of rescue medication, and cleaning and coating of spacers if applicable. These instructions were given and management plans were made by their asthma team, according to current national guidelines.

Usual care consisted of routine outpatient visits every 4 months (figure 1). During these visits, patients completed a digital version of the (C-)ACT to assess asthma control (result not accessible to the treating physician). Participants in the usual care group did not receive feedback on this score.

Asthma management using the VAC included outpatient visits every 8 months. In between these visits, asthma control was monitored online, filling in a (C-)ACT monthly (figure 1). If the (C-)ACT score was $\geqslant 20$, automatic default messages were emailed with positive and encouraging content. If the (C-)ACT score was $<20$, feedback to the participants included advice to check their medication use, an individual action plan and a request to contact their asthma team when symptoms persisted. In addition, feedback was sent to the asthma team with the request to contact the participant within 2 working days to address the clinical condition of that moment.

In case of a missing questionnaire, a reminder was automatically sent to the patient to complete the (C-)ACT. This reminder was send after 1 and 2 weeks. No extra chasing-up was done to receive missing questionnaire after 3 weeks.

In both groups, lung function (FEV1) and FENO were measured at baseline and after 8 and 16 months. These results were accessible to the treating physicians. In both groups, any intervention such as adjustment of treatment was at the judgement of the treating physician.

\section{Primary end-point}

The primary end-point was the number of SFDs in the last 4 weeks of the study. SFDs were defined as days without asthma symptoms. The number of SFDs was calculated based on data obtained from the (C-)ACT (details on derivation can be found in supplementary appendix S1).

\section{Secondary end-points}

Secondary outcomes were documented using a case report form: asthma control, FEV1, FENO, asthma exacerbations treated with systemic corticosteroids, unscheduled outpatient visits, hospital admissions and daily dose of ICSs.

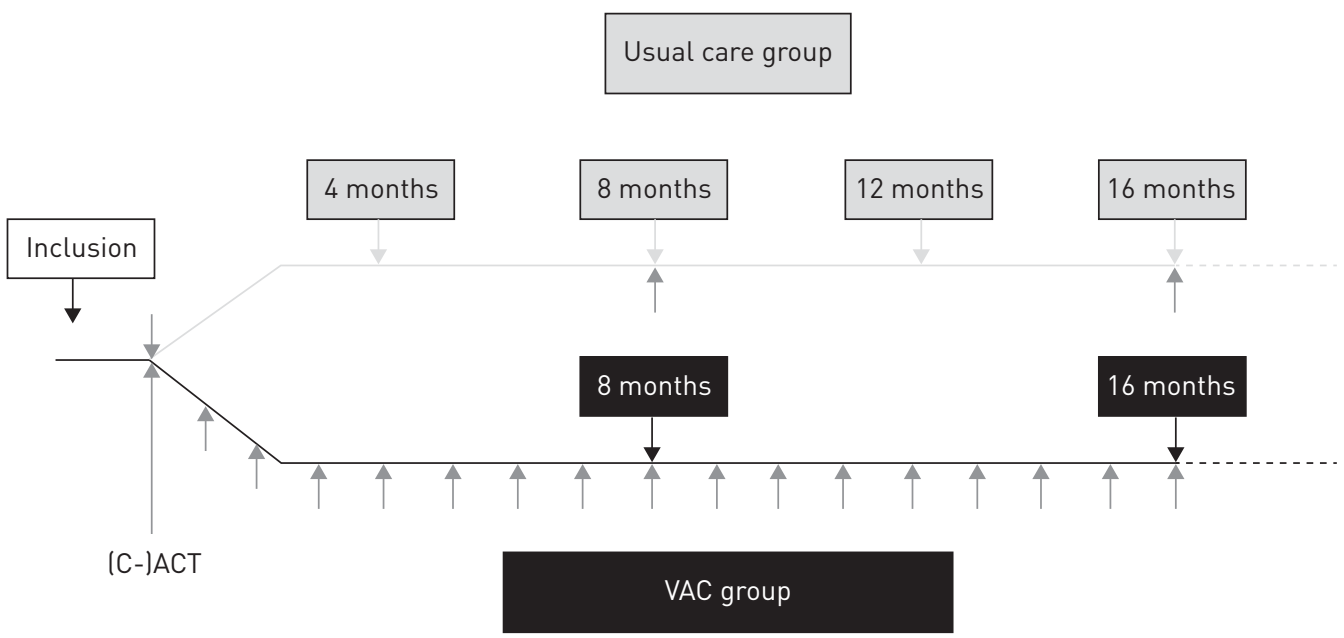

FIGURE 1 Overview of the study. (C-JACT: (Childhood) Asthma Control Test; VAC: virtual asthma clinic. 
Asthma control was measured by the Dutch validated web-based version of the C-ACT for young children or the ACT for older children [15]. An ACT score of $\leqslant 19$ points was considered as reflecting poorly or uncontrolled asthma [16]. The minimal important difference (MID) for clinical relevance was defined as 2 C-ACT points and 3 ACT points [17].

FEV1 and FENO were both measured according to American Thoracic Society/European Respiratory Society standards $[18,19]$. FEV1 was obtained before and 20 min after maximal bronchodilation with 400 (6-11 years) or 800 (12-16 years) $\mu \mathrm{g}$ salbutamol through a spacer, and expressed using Global Lung Function Initiative reference values [20]. FENO was assessed with a Niox Mino monitor (Aerocrine, Solna, Sweden) prior to spirometry and expressed in parts per billion.

\section{Statistical analyses}

The power calculation was based on data of SFDs in a similar population in which the mean \pm SD percentage of SFDs was $44 \pm 34 \%$ (range $0-100 \%$ ) and $58 \pm 40 \%$ (range $0-100 \%$ ) in a "usual care" and intervention group [21]. The current study was powered to detect such a $14 \%$ difference in SFDs, considered to be a clinically relevant difference and corresponding to 4 SFDs per month, with $80 \%$ probability, $\alpha=0.05$ (one-sided) in 91 children per group. A sample size of 105 participants was calculated, anticipating a dropout rate of $10 \%$.

Mean \pm standard deviation and median (interquartile range) were used to describe normally distributed and skewed data, respectively. For the primary end-points, the changes from baseline in the number of SFDs at 8 and 16 months were analysed using linear mixed models, and were corrected for baseline measurements and centre. Analyses on the secondary outcomes ((C-)ACT, FEV1 and FENO) were reported for two different age groups (i.e. young children (6-11 years) and older children (12-16 years)). The changes from baseline in these outcomes at 8 and 16 months were also analysed with linear mixed models and were only corrected for baseline, since there was no significant effect of centre as randomisation stratification variable. Differences in unscheduled visits, admissions, asthma exacerbations and courses of systemic corticosteroids were analysed using Mann-Whitney U-tests. SPSS version 21.0 (IBM, Armonk, NY, USA) was used.

\section{Results}

Data on the number of SFDs ((C-)ACT), lung function, FENO and ICS use were available in 76\%, 90\%, $81 \%$ and $93 \%$, respectively. All available data were used for the analyses.

\section{Randomisation and baseline characteristics}

Out of 343 invited children, 210 children (59.5\% males) consented to participate in the study, of whom 105 patients were allocated to usual care and 105 to care using the VAC (figure 2).

Baseline characteristics of the usual care group were not significantly different from the VAC group (table 1).

\section{Primary outcome}

The number of SFDs is presented in supplementary appendix S1.

For both groups, a statistically significant difference in the number of SFDs was demonstrated after 16 months, in favour of the VAC compared with usual care (difference of 1.23 days, 95\% CI $0.42-2.04$; $\mathrm{p}=0.003$ ) (figure 3).

\section{Secondary outcomes}

The secondary end-points after 16 months of follow-up are summarised in table 2 .

\section{Asthma control}

Figure $4 \mathrm{a}$ and $\mathrm{b}$ illustrate the differences in asthma control measured by the C-ACT and ACT, respectively.

For the C-ACT (figure 4a), a significant difference in mean outcome of 1.17 points (95\% CI 0.09-2.25; $\mathrm{p}=0.03$ ) in favour of VAC was demonstrated at 16 months compared with usual care in children 6-11 years of age.

In children 12-16 years of age (figure $4 \mathrm{~b}$ ), asthma control was similar after 16 months of follow-up, as the ACT score did not differ significantly between both groups ( 0.88 points, $95 \% \mathrm{CI}-0.41-2.16$; $\mathrm{p}=0.18$ ).

\section{Lung function, FENO and daily ICS dose}

Mean changes from baseline in FEV1 and FENO did not differ between groups (figure $5 \mathrm{a}$ and $\mathrm{b}$ ). After 16 months of follow-up, the mean value of FENO was similar in both groups (table 2).

At baseline, the mean daily ICS dose did not differ between both groups (table $1 ; \mathrm{p}=0.19$ ) and this did not differ after 16 months (data not presented). 


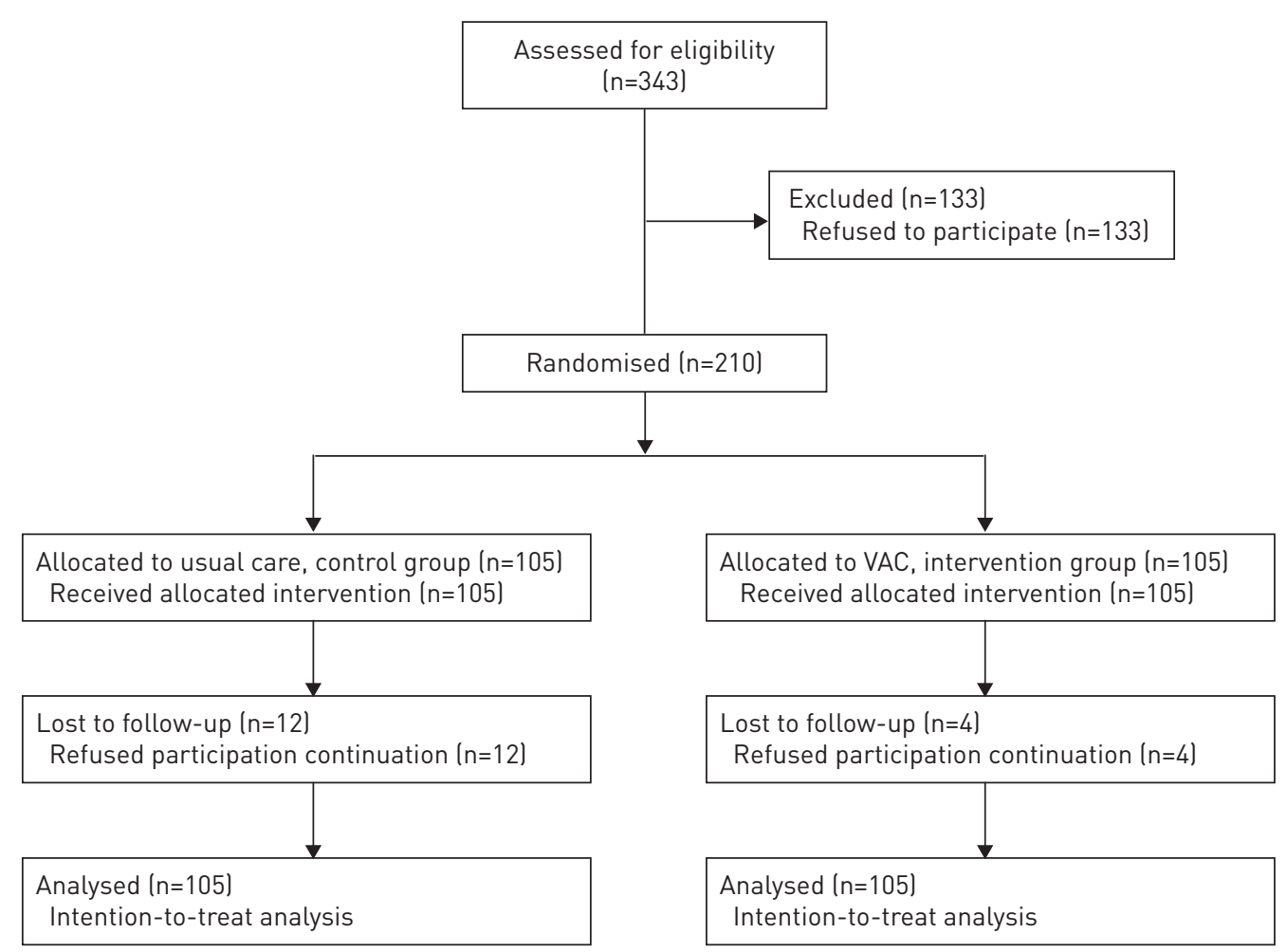

FIGURE 2 Flow diagram of participant selection. VAC: virtual asthma clinic.

Exacerbations, unscheduled outpatient visits and hospital admissions

The numbers of asthma exacerbations, telephone calls, unscheduled visits to the outpatient clinic or emergency department and hospital admissions were similar in both groups (table 3).

Subgroup analysis: poorly or uncontrolled asthma

Almost $30 \%$ of the children had uncontrolled asthma ((C-)ACT score $\leqslant 19)$ at the start of the study and this was similar in both groups: 28 and 30 children in the usual care and VAC groups, respectively. After a 16-month follow-up period the percentage of children with uncontrolled asthma decreased with both monitoring strategies: from $29 \%$ to $11 \%$ in the VAC group and from $27 \%$ to $11 \%$ in the usual care group.

\begin{tabular}{lcc}
\hline TABLE 1 Baseline characteristics & VAC \\
& Usual care & 105 \\
\hline Subjects & 105 & $11.3 \pm 2.9$ \\
Age years & $11.3 \pm 2.7$ & \\
Age group years & & $59(56.2 \%)$ \\
$\quad$ 6-11 & $63(60 \%)$ & $46(43.8 \%)$ \\
12-16 & $42(40 \%)$ & $64(61 \%)$ \\
Male & $61(58.1 \%)$ & $415 \pm 205$ \\
Initial ICS dose $\boldsymbol{\mu g}$-day-1\# & $461 \pm 244$ & $94.3 \pm 14.1$ \\
FEV1 \% pred & $93.6 \pm 14.1$ & $-0.48 \pm 1.2$ \\
FEV1 z-score & $-0.53 \pm 1.2$ & $27.1 \pm 24.1$ \\
FENo ppb & $29.5 \pm 26.3$ & $22(3.2)$ \\
C-ACT score & $21.1(4.0)$ & $20.9(3.6)$ \\
ACT score & $20.3(4.2)$ & $30(28.6)$ \\
IC-)ACT <20 points & $28(26.7)$ & $26.8 \pm 4.1$ \\
SFDs & $26.2 \pm 4.9$ & \\
\hline
\end{tabular}

Data presented as $n$, mean $\pm S D$ or median (interquartile range), unless otherwise stated. VAC: virtual asthma clinic; FEV1: forced expiratory volume in $1 \mathrm{~s}$; FENO: exhaled nitric oxide fraction; (C-)ACT: (Childhood) Asthma Control Test; SFD: symptom-free day. " : beclomethasone or equivalent dose. 
FIGURE 3 Mean \pm SD number of symptom-free days measured at baseline ( 0 months) and after 8 and 16 months of follow-up. VAC: virtual asthma clinic.

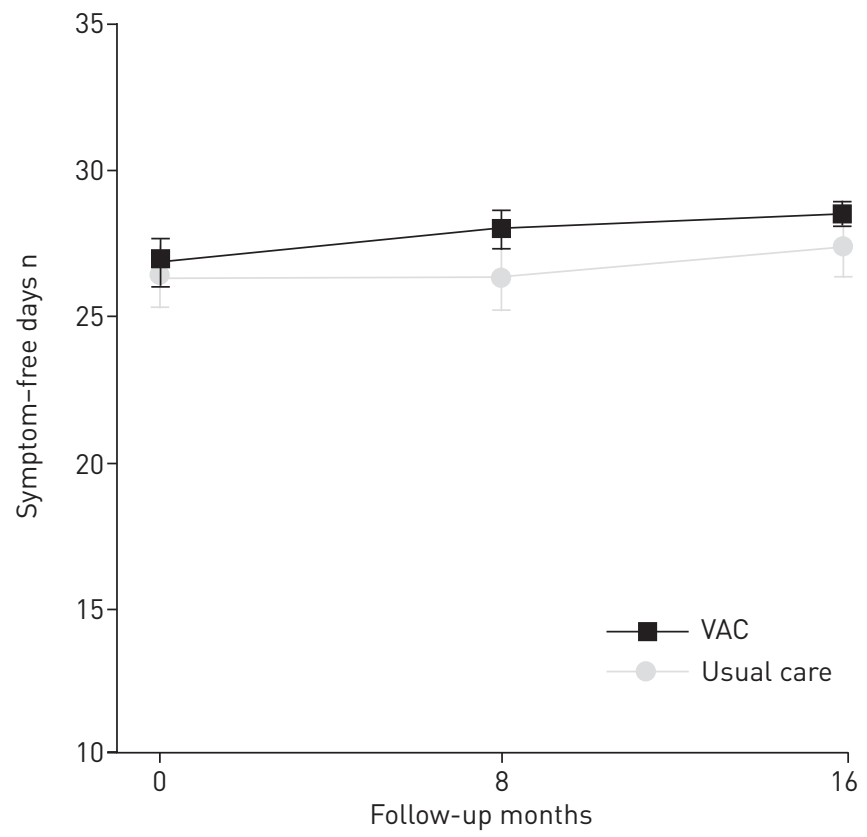

A post hoc analysis demonstrated that the improvement within the VAC and usual care groups could be attributed to children with uncontrolled asthma at baseline. In children 6-11 years of age with uncontrolled asthma, the C-ACT increased 5.4 points during the study $(\mathrm{p}<0.01)$ in the VAC group and increased 4.3 points $(\mathrm{p}=0.01)$ in the usual care group.

In children 12-16 years of age with uncontrolled asthma, a significant improvement of 3.7 ACT points $(\mathrm{p}<0.01)$ after 16 months occurred in the VAC group, whereas this improvement was not statistically significant in the usual care group.

\section{Discussion}

Principal findings

This study demonstrates that eHealth using the VAC can substitute $50 \%$ of routine outpatient visits in paediatric asthma care while the number of SFDs improved significantly after a 16-month follow-up. Although this improvement was of no clinical relevance based on the predicted improvement of 4 SFDs per month, this study provides strong evidence that the eHealth intervention for online asthma monitoring as used in this study can (partly) replace routine outpatient visits without deterioration of asthma control.

FEV1, FENO, mean daily dose of ICSs, number of asthma exacerbations, additional telephone calls, unscheduled visits to the outpatient clinic or emergency department, hospital admissions and courses of systemic corticosteroids were similar in both groups during 16 months.

\begin{tabular}{|c|c|c|c|c|}
\hline & Usual care & VAC & Difference $(95 \% \mathrm{CI})$ & p-value ${ }^{\#}$ \\
\hline SFDs & $27.3 \pm 3.6$ & $28.5 \pm 1.7$ & $1.23(0.42-2.04)$ & 0.003 \\
\hline C-ACT score & $22.3 \pm 3.9$ & $23.7 \pm 2.8$ & $1.17(0.09-2.25)$ & 0.03 \\
\hline ACT score & $21.3 \pm 3.3$ & $22.1 \pm 2.9$ & $0.88(-0.41-2.16)$ & 0.18 \\
\hline FEV $1 \%$ pred & $92.3 \pm 14.7$ & $92.1 \pm 13.5$ & $-1.01(-3.60-1.57)$ & 0.44 \\
\hline FEV1 z-score & $-0.68 \pm 1.1$ & $0.52 \pm 1.0$ & $-0.04(-2.50-0.16)$ & 0.70 \\
\hline FENO ppb & $30.3 \pm 24$ & $33.5 \pm 31.5$ & $4.19(-2.51-10.88)$ & 0.22 \\
\hline
\end{tabular}

Data presented as mean \pm SD, unless otherwise stated. SFD: symptom-free day; (C-)ACT: (Childhood) Asthma Control Test; FEV1: forced expiratory volume in $1 \mathrm{~s}$; FENO: exhaled nitric oxide fraction. ${ }^{\#}$ : $p$-values derived from linear mixed model analysis. 

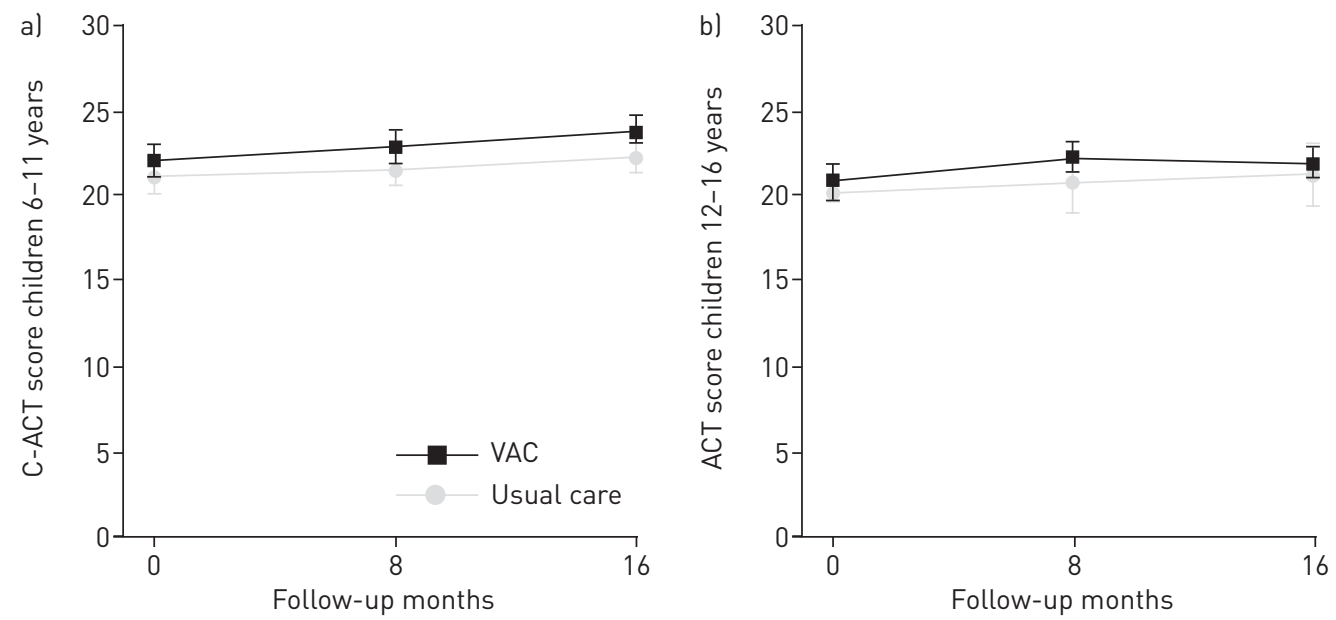

FIGURE 4 Changes in mean \pm SD a) Childhood Asthma Control Test (C-ACT) score in children aged 6-11 years. and b) ACT score in children aged 12-16 years at baseline (0 months) and after 8 and 16 months of follow-up. VAC: virtual asthma clinic.

Daily dose of ICS did not decrease in both groups, contrary to a recent study in children with asthma [8]. A reduction of medication in that study was realised in both the standard care and web-based care groups, with a larger reduction in the web-based group. An important difference is that treating physicians were instructed to reduce treatment based on the outcome of the various monitoring strategies, resulting in a decrease in daily dosages in all treatment arms. In our study, physicians were free to adapt treatment at their own decision in both treatment arms.

To the best of our knowledge, this is the first study to demonstrate that an eHealth intervention in daily practice can partly substitute routine outpatient visits. Earlier studies showed comparable or improved outcomes after web-based monitoring of asthma compared with usual care, with regard to lung function, adherence, quality of life, asthma control, knowledge and additional visits [2, 3, 5, 9, 10, 22-26]. However, these studies mainly assessed the additional value of eHealth compared with usual care and did not focus on its potential role in replacing it.

Another strength of the study is its external validity. The results of the study are easy to generalise to the general paediatric asthma population as four general hospitals and four tertiary hospitals across the country (both rural and urban areas) participated in this study.

The results of this study are subject to several limitations. First, SFDs were not collected by daily questionnaires but were extracted from the (C-)ACT. This may have led to an insufficient reflection of
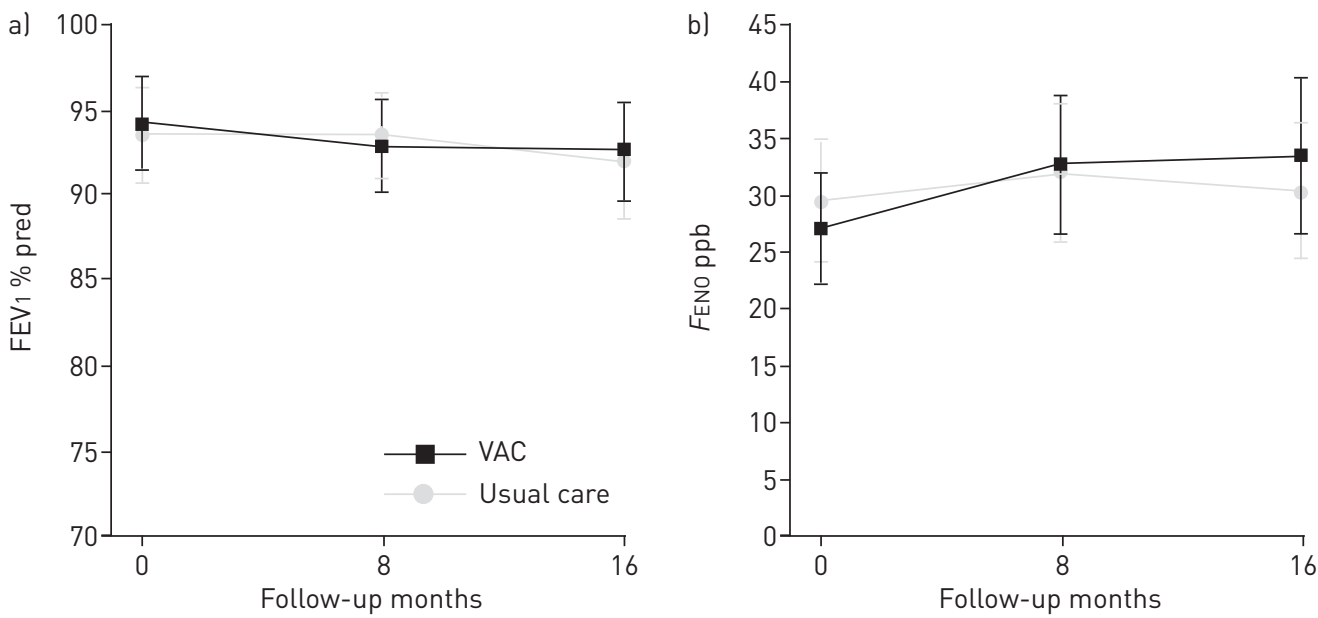

FIGURE 5 Changes in mean $\pm S D$ a) forced expiratory volume in $1 \mathrm{~s}\left(F E V_{1}\right)$ and $b$ ) exhaled nitric oxide fraction (FENO) for all participants measured at baseline $(0$ months) and after 8 and 16 months of follow-up. VAC: virtual asthma clinic. 
TABLE 3 Asthma exacerbations, unscheduled visits, courses of systemic corticosteroids and hospital admissions

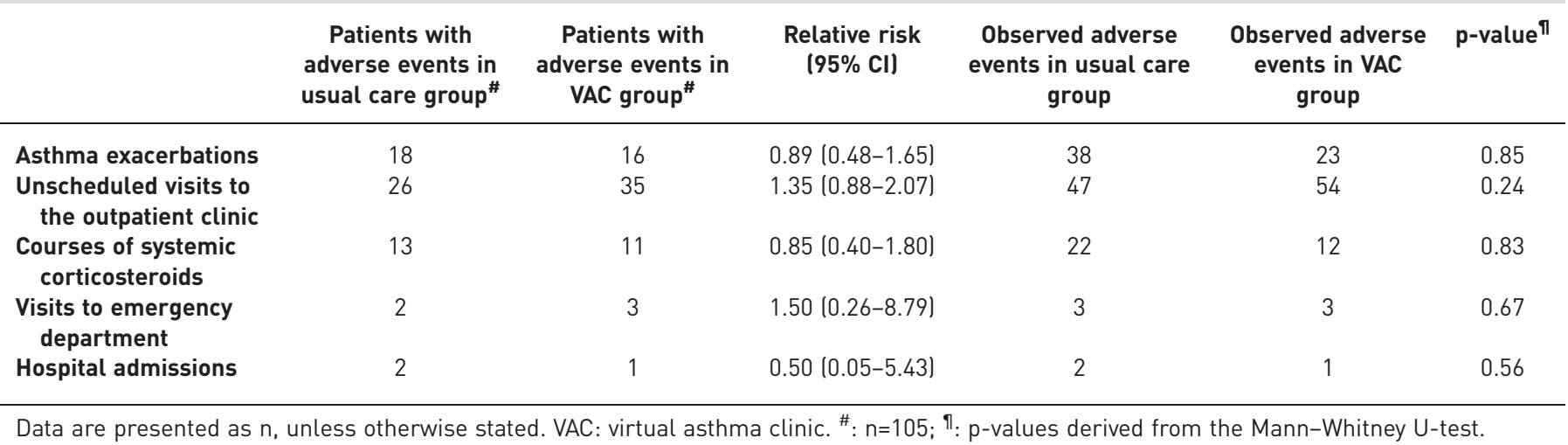

individual asthma symptoms. However, our target population clearly indicated that they were not keen on filling in daily diaries because they considered this as an unnecessary burden. In addition, it would not reflect daily practice and anticipated use of the VAC. Furthermore, previous studies reported that daily diaries are often falsified and unreliable [27, 28].

Second, despite the statistically significant improvement of 1.17 C-ACT points in young children, the MID of 2 C-ACT points was not reached in this study. The MID reflects a clinically meaningful change for the patients and has been shown to be $2 \mathrm{C}$-ACT points or $3 \mathrm{ACT}$ points [17, 29]. An explanation for this small difference might be that the majority of patients with well-controlled asthma at baseline had little potential for improvement during follow-up. Subgroup analysis confirmed that significant improvement of the (C-)ACT was only seen in children with uncontrolled asthma at baseline, possibly also due to regression to the mean.

In both groups, children with uncontrolled asthma also had better asthma control after 16 months of follow-up. This may be due to the fact that study participation increases the awareness of the disease, which could improve adherence to medication, and therefore asthma control (both in the VAC and usual care groups). Additionally, eHealth interventions seem to be most successful in patients with more severe illness or uncontrolled disease who have most to gain $[4,30]$. However, it is still unclear which patients might benefit most. Future research should focus on this subject and examine patient preferences to achieve personalised management $[8,13,31]$.

Third, one might argue that the outpatient visits in the usual care group, planned every 4 months, might not have been necessary and fewer contacts would also be sufficient to monitor asthma control. Although current international guidelines emphasise the importance of monitoring asthma, they do not give clear recommendations on monitoring frequency to obtain and maintain asthma control $[14,19,32,33]$. Some form of asthma monitoring is essential to reduce future risks for the patients. Nevertheless, it is still unknown which monitoring strategy is superior and what monitoring frequency is optimal. Ideally, any monitoring scheme should be tailored to the individual patient and follow-up should intensify according to asthma severity $[13,34]$. A less frequent follow-up in the usual care group could have resulted in a monitoring frequency too low to be acceptable.

Fourth, this study was limited by a potential selection bias despite well-defined inclusion criteria. Main inclusion criteria were an asthma diagnosis based on clinical symptoms and significant reversible airways obstruction, and/or airway hyperresponsiveness, and/or increased FENO. All patients did meet these criteria, but it is conceivable that selection bias occurred due to physicians inviting specific participants and avoiding patients with impairment in social interactions in the past (e.g. no show on clinical visits, problematic families). The use of the VAC might also have caused a selection bias due to the requirement for internet access, but not in this study since $>96 \%$ of the Dutch households had access to the internet in 2014 and this percentage is still increasing, while the increasing use of internet for management of chronic illnesses seems a natural development [35].

eHealth interventions for online asthma monitoring, like this VAC, offer new possibilities to transform the current supply-driven healthcare system to a more patient-centred approach and provide continuity of care tailored to the individual patient. This so-called "personalised eHealth" is needed to support self-management and is proposed as an appealing medium for health improvement as it can easily provide remote online monitoring in a time when healthcare systems are already overburdened and more frequent 
routine visits are not desirable. Furthermore, the VAC may serve as an example for other chronic diseases in which validated questionnaires play an important role in monitoring disease activity and detecting deterioration.

However, determination of the effect of eHealth solely in terms of clinical outcomes is not sufficient. Future research should focus on defining the cost-effectiveness of eHealth interventions, like the VAC, the possibilities to implement eHealth in routine clinical care, and to assess drivers and barriers for further implementation in paediatric asthma care.

\section{Conclusions}

While routine outpatient visits were reduced by $50 \%$, the number of SFDs and the degree of asthma control improved in children who received care using the VAC. Although these differences were statistically significant, we consider these as not clinically relevant. Hence, routine outpatient visits can partly be replaced by monitoring asthmatic children using eHealth.

\section{Acknowledgements}

We gratefully thank all participating children and parents for their contribution to this study, and thank the collaborating paediatricians, and Coosje Sintnicolaas (Dept of Paediatric Pulmonology, Amalia Children's Hospital, Radboud University Medical Centre, Nijmegen, The Netherlands), Petra Stevens (Dept of Paediatrics, Canisius Wilhelmina Hospital, Nijmegen, The Netherlands), Mariël Verwaal (Dept of Paediatrics, Maasstad Hospital, Rotterdam, The Netherlands), Carola Bolder (Dept of Paediatrics, Maxima Medical Centre, Veldhoven, The Netherlands), Ans Winters (Dept of Paediatric Pulmonology, Leiden University Medical Centre, Leiden, The Netherlands), Ineke Mulder (Dept of Paediatric Pulmonology, Juliana Children's Hospital, Haga Hospital, The Hague, The Netherland), Christine van Baak (Dept of Paediatric Pulmonology, Juliana Children's Hospital, Haga Hospital, The Hague, The Netherlands), Magda Spierings (Dept of Paediatric Pulmonology, Sophia Children's Hospital, Erasmus Medical Centre, Rotterdam, The Netherlands) and Jantine Hiddinga (Dept of Paediatric Pulmonology, Sophia Children's Hospital, Erasmus Medical Centre, Rotterdam, The Netherlands) for their enthusiasm and their efforts in recruiting and monitoring the patients. We acknowledge Wim Hop (Dept of Biostatistics, Erasmus Medical Centre, Rotterdam, The Netherlands) and Henriëtte Moll (Dept of Paediatric Pulmonology, Sophia Children's Hospital, Erasmus Medical Centre, Rotterdam, The Netherlands) for performing the interim safety analysis. We also commemorate Rene van Gent (Dept of Paediatrics, Maxima Medical Centre, Veldhoven, The Netherlands) and thank him for his contributions to this study.

Author contributions: P.J.F.M. Merkus, M.W. Pijnenburg and C.M. Verhaak: designed the study and obtained funding. L.S. van den Wijngaart, J. Roukema, A.L.M. Boehmer, M.L. Brouwer, C.A.C. Hugen, L.E.M. Niers, A.J. Sprij, E.R.V.M. Rikkers-Mutsaerts, B.L. Rottier, M.W. Pijnenburg and P.J.F.M. Merkus: all participated as investigators in this trial, recruited patients and performed treatments. L.S. van den Wijngaart and A.R.T. Donders: carried out the analyses. L.S. van den Wijngaart, J. Roukema, and P.J.F.M. Merkus: operated as the writing committee and drafted the manuscript until it reached its final form. All authors commented on the manuscript and its revisions. P.J.F.M. Merkus: guarantor of the study.

\section{References}

$1 \quad$ Sullivan CE. Cybersupport: empowering asthma caregivers. Pediatr Nurs 2008; 34: 217-224.

2 van der Meer V, van Stel HF, Detmar SB, et al. Internet-based self-management offers an opportunity to achieve better asthma control in adolescents. Chest 2007; 132: 112-119.

3 van Gaalen JL, Beerthuizen T, van der Meer V, et al. Long-term outcomes of internet-based self-management support in adults with asthma: randomized controlled trial. J Med Internet Res 2013; 15: e188

$4 \quad$ McLean S, Protti D, Sheikh A. Telehealthcare for long term conditions. BMJ 2011; 342: d120.

5 McLean S, Chandler D, Nurmatov U, et al. Telehealthcare for asthma: a Cochrane review. CMAJ 2011; 183: E733-E742.

6 Zhao J, Zhai YK, Zhu WJ, et al. Effectiveness of telemedicine for controlling asthma symptoms: a systematic review and meta-analysis. Telemed J E Health 2015; 21: 484-492.

7 Bussey-Smith KL, Rossen RD. A systematic review of randomized control trials evaluating the effectiveness of interactive computerized asthma patient education programs. Ann Allergy Asthma Immunol 2007; 98: 507-516.

8 Voorend-van Bergen S, Vaessen-Verberne AA, Brackel HJ, et al. Monitoring strategies in children with asthma: a randomised controlled trial. Thorax 2015; 70: 543-550.

9 Chan DS, Callahan CW, Hatch-Pigott VB, et al. Internet-based home monitoring and education of children with asthma is comparable to ideal office-based care: results of a 1-year asthma in-home monitoring trial. Pediatrics 2007; 119: 569-578.

10 Chan DS, Callahan CW, Sheets SJ, et al. An Internet-based store-and-forward video home telehealth system for improving asthma outcomes in children. Am J Health Syst Pharm 2003; 60: 1976-1981.

11 Runge C, Lecheler J, Horn M, et al. Outcomes of a web-based patient education program for asthmatic children and adolescents. Chest 2006; 129: 581-593.

12 Wiecha JM, Adams WG. BostonBreathes: improving pediatric asthma care with a home-based interactive website for patient education, monitoring, and clinical teamwork. AMIA Annu Symp Proc 2006; 2006: 1144

13 Pijnenburg MW, Baraldi E, Brand PL, et al. Monitoring asthma in children. Eur Respir J 2015; 45: 906-925.

14 Global Initiative for Asthma. Global Strategy for Asthma Management and Prevention. 2017. http://ginasthma.org/ 2017-gina-report-global-strategy-for-asthma-management-and-prevention Date last accessed: July 2, 2017.

15 Koolen BB, Pijnenburg MW, Brackel HJ, et al. Validation of a web-based version of the asthma control test and childhood asthma control test. Pediatr Pulmonol 2011; 46: 941-948.

16 Juniper EF, O'Byrne PM, Guyatt GH, et al. Development and validation of a questionnaire to measure asthma control. Eur Respir J 1999; 14: 902-907. 
17 Voorend-van Bergen S, Vaessen-Verberne AA, Landstra AM, et al. Monitoring childhood asthma: web-based diaries and the asthma control test. J Allergy Clin Immunol 2014; 133: 1599-1605.

18 Beydon N, Davis SD, Lombardi E, et al. An official American Thoracic Society/European Respiratory Society statement: pulmonary function testing in preschool children. Am J Respir Crit Care Med 2007; 175: 1304-1345.

19 Reddel HK, Taylor DR, Bateman ED, et al. An official American Thoracic Society/European Respiratory Society statement: asthma control and exacerbations: standardizing endpoints for clinical asthma trials and clinical practice. Am J Respir Crit Care Med 2009; 180: 59-99.

20 Quanjer PH, Stanojevic S, Cole TJ, et al. Multi-ethnic reference values for spirometry for the 3-95-yr age range: the global lung function 2012 equations. Eur Respir J 2012; 40: 1324-1343.

21 Pijnenburg MW, Bakker EM, Hop WC, et al. Titrating steroids on exhaled nitric oxide in children with asthma: a randomized controlled trial. Am J Respir Crit Care Med 2005; 172: 831-836.

22 Rasmussen LM, Phanareth $\mathrm{K}$, Nolte $\mathrm{H}$, et al. Internet-based monitoring of asthma: a long-term, randomized clinical study of 300 asthmatic subjects. J Allergy Clin Immunol 2005; 115: 1137-1142.

23 Morrison D, Wyke S, Agur K, et al. Digital asthma self-management interventions: a systematic review. J Med Internet Res 2014; 16: e51.

24 Jan RL, Wang JY, Huang MC, et al. An internet-based interactive telemonitoring system for improving childhood asthma outcomes in Taiwan. Telemed J E Health 2007; 13: 257-268.

25 Araujo L, Jacinto T, Moreira A, et al. Clinical efficacy of web-based versus standard asthma self-management. J Investig Allergol Clin Immunol 2012; 22: 28-34.

26 Rikkers-Mutsaerts ER, Winters AE, Bakker MJ, et al. Internet-based self-management compared with usual care in adolescents with asthma: a randomized controlled trial. Pediatr Pulmonol 2012; 47: 1170-1179.

27 Brand PL, Roorda RJ. Usefulness of monitoring lung function in asthma. Arch Dis Child 2003; 88: 1021-1025.

28 Kamps AW, Roorda RJ, Brand PL. Peak flow diaries in childhood asthma are unreliable. Thorax 2001; 56: $180-182$.

29 Schatz M, Sorkness CA, Li JT, et al. Asthma Control Test: reliability, validity, and responsiveness in patients not previously followed by asthma specialists. J Allergy Clin Immunol 2006; 117: 549-556.

30 McLean S, Sheikh A, Cresswell K, et al. The impact of telehealthcare on the quality and safety of care: a systematic overview. PLoS One 2013; 8: e71238.

31 Pijnenburg MW, Szefler S. Personalized medicine in children with asthma. Paediatr Respir Rev 2015; 16: 101-107.

32 British Thoracic Society/Scottish Intercollegiate Guidelines Network. British guideline on the Management of Asthma. Thorax 2008; 63: Supp. 4, iv1-iv121.

33 National Asthma Education and Prevention Program. Expert Panel Report 3 (EPR-3): Guidelines for the Diagnosis and Management of Asthma Summary Report 2007. J Allergy Clin Immunol 2007; 120: 5 Suppl., S94-S138.

34 Brouwer ML, Wijngaart LS, Hugen CA, et al. Evaluation of monitoring strategies for childhood asthma. Expert Rev Respir Med 2016; 10: 1199-1209.

35 Centraal Bureau voor de Statistiek. ICT, Kennis en Economie 2014. [ICT, Knowledge and Economics 2014.] 2014. www.cbs.nl/NR/rdonlyres/4DEFB273-9BC7-459B-8788-44C94175DA4B/0/2014i78pub.pdf Date last accessed: July $2,2017$. 